Review

\title{
Effect of biomaterials on angiogenesis during vital pulp therapy
}

\author{
Mohammad Ali SAGHIRI ${ }^{1}$, Armen ASATOURIAN ${ }^{2}$, Franklin GARCIA-GODOY ${ }^{3}$ and Nader SHEIBANI ${ }^{1}$ \\ ${ }^{1}$ Departments of Ophthalmology and Visual Science and Biomedical Engineering, University of Wisconsin, School of Medicine and Public Health, \\ Madison, WI, USA \\ ${ }^{2}$ Angiogenesis and Regenerative Sector, Dr. H Afsar Lajevardi Cluster, Shiraz, Iran \\ ${ }^{3}$ Bioscience Research Center, University of Tennessee Health Science Center, TN, USA \\ Corresponding author, Mohammad Ali SAGHIRI; E-mail: Saghiri@gmail.com
}

\begin{abstract}
This review intended to provide an overview of the effects of dental materials, used in dentin-pulp complex and dental pulp regeneration, on angiogenesis processes during regenerative endodontic procedures. An electronic search was performed in PubMed and MEDLINE databases via OVID using the keywords mentioned in the PubMed and MeSH headings for English language published articles from January 2005-April 2014 that evaluated the angiogenic properties of different dental materials used in regenerative endodontic procedures. Of the articles identified in an initial search, only 40 articles met the inclusion criteria set for this review. Vital pulp therapy materials might have positive effects on angiogenesis events, while most of the canal irrigating solutions and antibiotic pastes have anti-angiogenic activity except for EDTA. Future clinical studies will be helpful in defining the mechanisms of action for dental materials that promote or inhibit angiogenesis events at applied areas.
\end{abstract}

Keywords: Angiogenesis, Dentin-pulp complex, Regeneration, Stem cells

\section{INTRODUCTION}

Regenerative endodontic has gained widespread interest in recent years as it is attempting to fill the root canal space with living tissues instead of artificial materials ${ }^{1}$. Most of dental materials release inorganic trace elements ${ }^{2-5)}$, and most of inorganic trace elements regulate angiogenesis ${ }^{6,7}$. In the field of regenerative endodontics the most important goal is to provide a suitable environment for the regeneration of healthy tissue and restore the lost biological tissues ${ }^{8}$. Based on the treatment site, this field is divided into two distinct categories of dentin-pulp complex regeneration and dental pulp regeneration ${ }^{1,8}$. The dentin-pulp complex regenerative procedures or vital pulp therapies include the direct pulp capping, indirect pulp capping, and pulpotomy. Direct pulp capping is defined as covering an exposed dental pulp with a protective agent and indirect pulp capping is referred to the application of a protective agent, on a thin layer of dentin over the nearly exposed dental pulp ${ }^{4}$. The other treatment in vital pulp therapies is the pulpotomy. It is defined as the surgical removal of inflamed coronal part of the dental pulp in the exposed pulpal tissue to save the remaining healthy tissue ${ }^{5}$. In dentin-pulp complex regeneration, clinicians attempt to provide an effective pulp capping with appropriate sealing ability ${ }^{5}$, and maintain the vitality of irritated pulp tissues and promote the formation of a dentinal bridge $^{8-10)}$ and other tissues including neural cells ${ }^{11)}$. In these procedures, the progenitor dental pulp stem cells (DPSCs) are migrated, recruited, and differentiated into odontoblast-like cells, which have the ability to produce

Color figures can be viewed in the online issue, which is available at J-STAGE.

Received Oct 3, 2015: Accepted Feb 10, 2016

doi:10.4012/dmj.2015-332 JOI JST.JSTAGE/dmj/2015-332 reparative dentin ${ }^{9,12)}$. Although, this issue seems very simple in theory, in reality the whole process is possible if the homeostasis of pulp is reestablished ${ }^{8}$. In other words, restorations of the vascular network, through up- or down regulation of pro- or anti-angiogenic growth factors, is a key determinant component that guides the regenerative procedure toward survival or necrosis of pulp tissue ${ }^{13)}$.

The second field of regenerative endodontics deals with regeneration of dental pulp tissue in necrotic teeth $^{14,15}$. In this procedure the treatment is initiated with the complete removal of necrotic dental pulp tissue, which is referred to as pulpectomy, by instrumentation and irrigation that is followed by disinfecting the root canal space $^{16)}$. After canal preparation, the regenerative treatment, the revascularization process, begins with instrumentation of periapical tissue to cause bleeding into the canal space. The blood clot formed inside the canal provides a provisional matrix scaffold for the recruited stem cells from apical papilla ${ }^{17}$. It is also demonstrated that complete disinfection plays a key role in the successful treatment outcomes ${ }^{18,19)}$.

Beside the stem cells derived from apical papilla, other investigators have used tissue engineered DPSCs for transplantation into the empty canal ${ }^{20)}$. In this treatment protocol, the establishment of a functional vascular network in transplanted tissue is the challenging goal for a successful result ${ }^{21}$. The formation of this vascular structure is possible through angiogenesis, which is defined as the formation of new blood vessels from pre-existing vasculature ${ }^{22)}$. In addition to regeneration of dental pulp tissue, apexogenesis and apexification are other endodontic procedures that are performed in immature permanent 
teeth $^{23)}$. Apexogenesis is the procedure that enables the immature permanent teeth to continue root end development, while the apexification provides a calcified barrier at the end of immature root by biocompatible material next to periapical tissue ${ }^{23)}$. It has been reported that the revascularization process occurs through the angiogenesis events derived from the periapical tissues that grow into the engineered pulp tissue. Furthermore, the immature teeth with open apices are the best candidates for these regenerative procedures ${ }^{24}$.

These facts emphasize angiogenesis as an important factor involved in homeostasis of dentin-pulp complex and dental pulp regeneration ${ }^{25)}$. In addition, angiogenesis has a pivotal role in dentinal and dental pulp tissues' regenerative and reparative procedures ${ }^{1,9)}$. The present study attempts to review the effects of dental materials and treatment modalities used in dentin-pulp complex and dental pulp regeneration on angiogenesis. The possible influences of dental procedures and materials on angiogenesis events are reviewed.

\section{MATERIALS AND METHODS}

The review purpose

In this review, the effects of dental treatments and materials used in direct or indirect pulp capping, pulpotomy, pulpectomy, apexogenesis, and apexification were overviewed on dental pulp tissue regeneration and revascularization. The main aspect of this review is to evaluate the possible influence of dental procedures and materials used in regenerative procedures, which can either promote or inhibit angiogenesis, during regeneration or revascularization.

\section{Inclusion and exclusion criteria}

The inclusion criteria were: 1) studies accepted and published in English language between January 2005-April 2014; 2) the scientific in-vivo, ex-vivo, or invitro articles, reviews, systematic reviews, case reports, and clinical trials with controlled study design; 3) studies that had evaluated the effect dental materials used in regenerative endodontics, direct or indirect pulp capping, pulpotomy, pulpectomy, apexogenesis, and apexification treatments on angiogenesis processes occurring in the applied area.

The exclusion criteria were: 1) studies that were published before January 2005 or after April 2014; 2) studies that did not evaluate the direct angiogenic potentials of the dental materials used in regenerative endodontics, direct or indirect pulp capping, pulpotomy, pulpectomy, apexogenesis, and apexification treatments; 3) studies that mainly focused on other aspects of dental materials, which have no effect on angiogenesis process.

\section{Search methodology}

An electronic search was performed in PubMed and MEDLINE databases via OVID using the keywords mentioned in the PubMed and MeSH headings for English language published articles from January

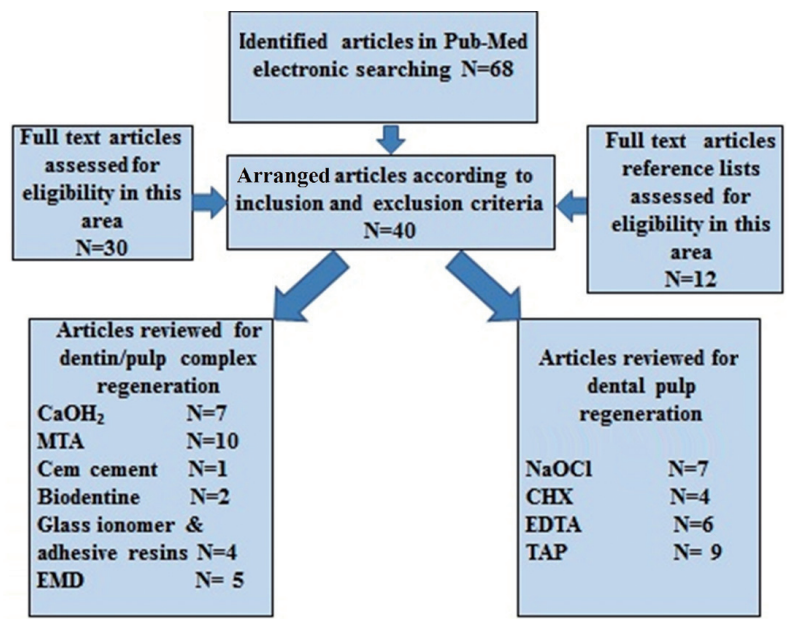

Fig. 1 A flowchart of search strategy to identify English articles from January 2005-April 2014 based on inclusion and exclusion criteria in this review study.

2005-April 2014 that evaluate the angiogenic properties of different dental materials used in regenerative endodontic procedures.

\section{Search strategy}

The electronic searching key words in PubMed and MEDLINE databases included: angiogenesis, pulp stem cells, regenerative endodontics, direct or indirect pulp capping, pulpotomy, pulpectomy, apexogenesis, apexification treatments and dental materials including calcium hydroxide, mineral trioxide aggregate, Bioaggregate, Cem cement, Biodentine, glass ionomer, adhesive resin, and enamel matrix derivatives in evaluation of dental pulp tissue regeneration and revascularization. Some of the most relevant article's full texts and reference lists were evaluated for eligibility. A flowchart of mentioned activities is presented in Fig. 1 to clarify the number of relevant articles used for this review.

\section{THE EFFECT OF DENTAL TREATMENTS AND MATERIALS ON ANGIOGENESIS IN DENTIN-PULP COMPLEX REGENERATION}

\section{Direct or indirect pulp capping and pulpotomy}

1. Calcium hydroxide

The introduction of vital pulp therapies including direct or indirect pulp capping date back to 1939 by Zander ${ }^{26)}$. An ideal pulp capping material should provide easy handling, infection control, good sealing ability, and induce dentinal bridge formation ${ }^{27)}$. Among several materials, calcium hydroxide $\left(\mathrm{Ca}(\mathrm{OH})_{2}\right)$ was one of the most common material used in pulp capping ${ }^{28)}$. Schröder indicated that $\mathrm{Ca}(\mathrm{OH})_{2}$ can induce a limited necrotic zone on the surface of pulp tissue at the application sites $^{28)}$. Due to its alkalinity, $\mathrm{Ca}(\mathrm{OH})_{2}$ has antibacterial activity and stimulates dentin formation ${ }^{29)}$.

The effect of $\mathrm{Ca}(\mathrm{OH})_{2}$ on dentin-pulp complex 
regeneration has been evaluated by several authors. Ji et al. indicated that $\mathrm{Ca}(\mathrm{OH})_{2}$ increases the recruitment, migration, proliferation, and mineralization of DPSCs, and periodontal ligament stem cells (PDLSCs) through the expression of STRO-1 and CD146 markers ${ }^{30}$. Sangwan et al. reviewed the mechanisms of action of $\mathrm{Ca}(\mathrm{OH})_{2}$ in tertiary dentinogenesis ${ }^{31)}$. They indicated that the regenerative effects of $\mathrm{Ca}(\mathrm{OH})_{2}$ are due to calcium ion release and the high $\mathrm{pH}$ value ${ }^{31}$. Calcium ions promote the migration of pulp progenitor cells, increase the synthesis of biomolecules such as fibronectin and bone morphogenic proteins (BMPs), and participate in mineralization ${ }^{31)}$.

The alkaline $\mathrm{pH}$ can present antibacterial and antiinflammatory effects, activate transforming growth factor $\beta$ (TGF- $\beta$ ), increase the activity of alkaline phosphatase (ALP), and enhance the dissolution of dentine extracellular matrix $(\mathrm{ECM})^{31}$.

The pro-angiogenic effects of $\mathrm{Ca}(\mathrm{OH})_{2}$ is mainly attributed to the release of growth factors preserved in the dentin matrix including TGF- $\beta$, platelet-derived growth factor (PDGF), fibroblast growth factor (FGF), and insulin-like growth factor (IGF) ${ }^{31)}$ (Fig. 2B). This issue was also discussed by Chun et al. where they demonstrated that chelating agents such as ethylenediaminetetraacetic acid (EDTA) can dissolve the dentin matrix and release pro-angiogenic factors, and promote the regenerative process ${ }^{32}$. Roberts-Clark and Smith demonstrated that in addition to PDGF and FGF-2, dentine matrix also contains vascular endothelial growth factor (VEGF) ${ }^{33)}$, which is one of the most important factors in angiogenesis events ${ }^{34}$. Løvschall et al. introduced another mechanism that $\mathrm{Ca}(\mathrm{OH})_{2}$ can influence angiogenesis process ${ }^{35}$. They suggested that this pulp capping material can activate notch signaling pathway, which is implicated in cell-cell interactions involved in many regenerative processes such as angiogenesis ${ }^{36)}$. In dental pulp tissue, this signaling pathway is activated due to injury, and participates in differentiation of stem cells to odontoblast-like and perivascular cells ${ }^{35}$. Previously, Iso et al. reported that notch signaling plays an active role in angiogenesis including the proliferation and migration of endothelial cells, smooth muscle, and arterial-venous differentiation $^{36)}$ (Fig. 2D).

\section{MTA}

Mineral trioxide aggregate (MTA) is another commonly used dental material in pulp capping treatments with more advantages over $\mathrm{Ca}(\mathrm{OH})_{2}{ }^{37}$. MTA has been recently optimized in many aspects including the setting time ${ }^{3)}$ and calcium ion release ${ }^{38}$. Al-Hezaimi et al. compared the regenerative effects of Portland cement and MTA with $\mathrm{Ca}(\mathrm{OH})_{2}$ and indicated that the thickness of reparative dentin was thicker in MTA and Portland cement, while the quality was not different ${ }^{37}$. Cavalcanti et al. showed that MTA, $\mathrm{Ca}(\mathrm{OH})_{2}$, and Single Bond adhesive system can increase the release of IL8 , while the release of interleukin- $1 \beta$ (IL- $1 \beta$ ) was only increased in samples treated with $\mathrm{MTA}^{39)}$. IL- $1 \beta$ is a pro-inflammatory cytokine which is secreted after tissue injury and induces the release of chemokines such as IL-8, which is considered a pro-angiogenic factor ${ }^{40)}$. Similar results were noticed by Ferreira et al., which evaluated the effect of pulpotomy agents including $\mathrm{Ca}(\mathrm{OH})_{2}$, MTA, adhesive resin, and formocresol on dental pulp tissue fibroblasts ${ }^{41}$. These authors reported that MTA was the only pulpotomy material which increased the release of IL- $1 \beta$ and IL- 8 by fibroblasts. Calcium hydroxide only stimulated the release of IL- $1 \beta$, while adhesive resin and formocresol could increase IL- 8 levels $^{41)}$ (Fig. 2D).

Zhang et al. reported that MTA had a greater potential for expression of TGF- $\beta 1$ in rat dental pulp tissue compared with $\mathrm{Ca}(\mathrm{OH})_{2}{ }^{42)}$. Paranjpe et al. demonstrated that MTA had positive effects on angiogenesis and differentiation of dental pulp cells when it was placed in direct contact with dental pulp ${ }^{43)}$. These authors reported that MTA, as a direct pulp capping agent, can induce the expression of VEGF, osteocalcin and dentin sialoprotein ${ }^{43,44)}$.

Zhang et al. evaluated the effect of MTA and $\mathrm{Ca}(\mathrm{OH})_{2}$ on expression of inducible nitric oxide synthase (iNOS) in rat dental pulp tissue ${ }^{45}$. These pulp capping materials increased the expression of iNOS 3 days after their application ${ }^{45}$. Ziche et al. indicated that NO plays an important role in regulating the angiogenesis process through the enhancement of endothelial cells proliferation and migration ${ }^{46)}$. Huang et al. indicated that MTA could activate mitogen-activated protein kinase (MAPK), specifically the p38 signaling pathway in $\mathrm{hDPSCs}^{47)}$. The in vitro culture of hDPSCs with MTA facilitated their differentiation, and also increased the expression of angiogenic factors including von Willebrand factor (vWF) and angiopoietin-1 (Ang-1) ${ }^{47)}$ (Fig. 2D).

\section{CEM cement}

Calcium-enriched mixture (CEM) cement is one of the pulp capping agents, which has osteogenic, cementogenic and dentinogenic functions ${ }^{48)}$. Asgary et al. compared the ability of CEM and MTA as capping agents. They concluded that CEM could increase the expression of FGF-4 and bone morphogenic protein 2 (BMP-2), while MTA positively affected the expression of TGF- $\beta 1$ in pulp tissue ${ }^{48)}$ (Fig. 2D).

\section{Biodentine}

Biodentine (Septodont, Saint-Maur-des-Fossès, France) is a tricalcium silicate-based cement, which has been recently introduced as a pulp capping material ${ }^{49}$. Luo et al. reported that the induction effect of Biodentine cement on differentiation of DPSCs is through the mitogen-activated protein kinase (MAPK) and calcium/ calmodulin-dependent protein kinase II (CaMKII) pathways ${ }^{49)}$. The angiogenic effect of this cement was evaluated by Laurent et al. who suggested that Biodentine can induce early mineralization in dental pulp due to an increase in release of TGF- $\beta 1$, a proangiogenic factor produced by pulp cells ${ }^{50)}$ (Fig. 2D). 


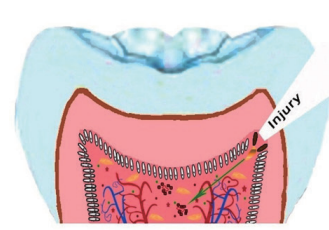

A. Activation

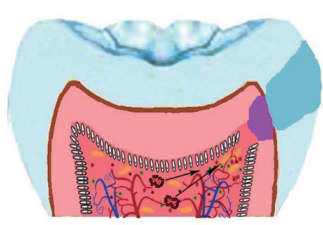

C. Migration

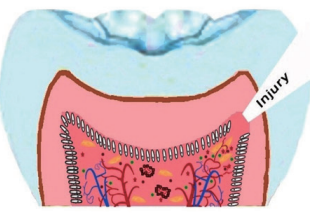

B. Proliferation effector FGF-2

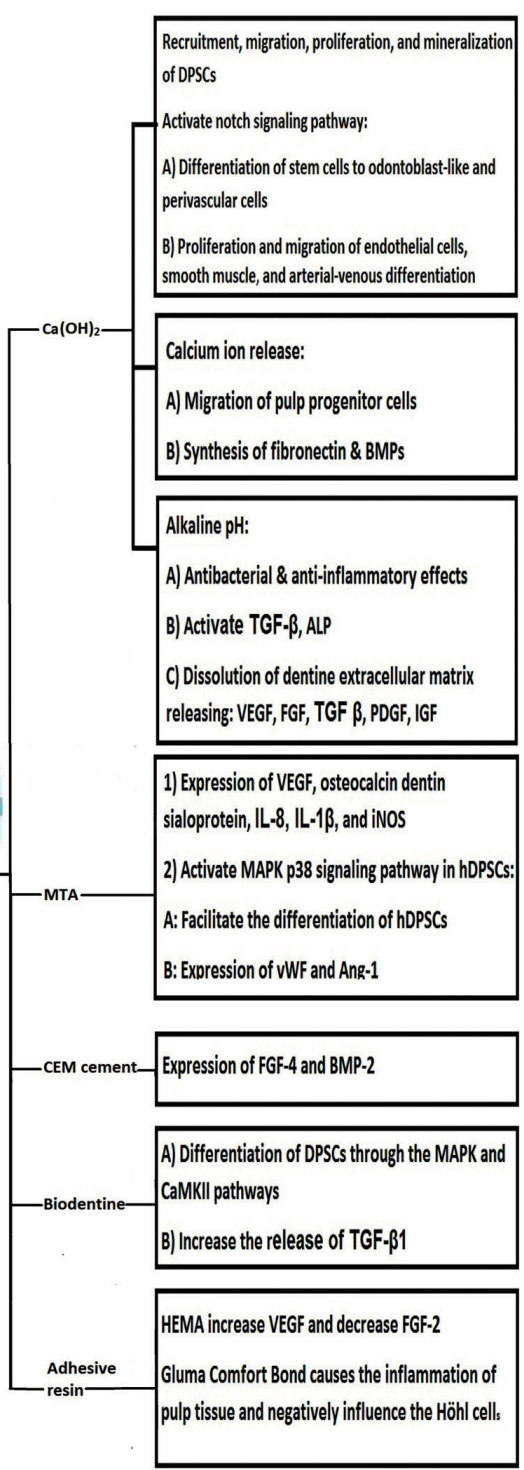

Fig. 2 Schematic presentation of dentin-pulp complex regeneration.

A: deep injury imposed to the pulp tissue, which activates regenerative processed; B: Recruitment of pulp stem cells and expression of angiogenic factors such as FGF-2, which are responsible for proliferation of endothelial cells; C: Migration of proliferated endothelial cells to the injured area; D: The angiogenic effects of different pulp capping materials in the regenerative processes; E: Differentiation of stem cells to odontoblast-like cells and secretion of reparative dentin. Please note the vascular structure returning to its normal architecture at the end of the regeneration process.

\section{Glass ionomer and adhesive resins}

Lutfi et al. showed that glass ionomer cement (GIC) as a lining material can act similar to $\mathrm{Ca}(\mathrm{OH})_{2}$ in inducing proliferative activity in dental pulp of exfoliated deciduous teeth ${ }^{51)}$. Dammaschke et al. compared the effect of dentine adhesive Gluma Comfort Bond (GCB) and $\mathrm{Ca}(\mathrm{OH})_{2}$ on the proliferation of pulp cells and concluded that GCB, due to its missing antibacterial efficacy and foreign body reactions, causes the inflammation of pulp tissue. Direct contact of GCB with dental pulp could increase the number of fibroblasts and endothelial cells in granulation tissue and negatively influence the Höhl cells ${ }^{52)}$ (Fig. 2D).

Adhesive systems have also been used as dental pulp capping agents. Tran-Hung et al. evaluated the effect of HEMA on secretion of pro-angiogenic factors in dental pulp after mechanical injury ${ }^{53)}$. They indicated that HEMA can increase the level of VEGF, decrease the expression of FGF-2, and has no effect on platelet derived growth factor-AB (PDGF-AB) in mechanically injured human dental pulp tissue ${ }^{53)}$. Similar results were reported by Mantellini et al. who demonstrated 
that HEMA or SingleBond adhesive resin could increase the expression of pro-angiogenetic factor VEGF in mouse odontoblast-like cells (MDPC-23) and macrophages, while this up-regulation was not observed in the undifferentiated mouse pulp cells and gingival fibroblasts $^{13)}$ (Fig. 2D). However, other investigators demonstrated that in case of mechanically exposed dental pulp, the application of dentine adhesive systems cannot induce the formation of an acceptable tertiary dentine bridge at applied area ${ }^{54)}$.

\section{Enamel matrix derivative (EMD)}

Guven et al. demonstrated that enamel matrix derivative (EMD) can also be used as a pulp capping material $^{55)}$. These authors showed that EMD was more capable of inducing the differentiation and proliferation of human tooth germ stem cells (hTGSCs) compared with calcium hydroxide-containing cement (DYCAL) and mineral trioxide aggregate $(\mathrm{MTA})^{55)}$. Even the EMD-coated DYCAL was shown to be less toxic, which emphasizes the biocompatible nature of $\mathrm{EMD}^{55}$. Yuan et al. demonstrated that EMD can exhibit angiogenic effects by presenting chemotactic effect on human umbilical vein endothelial cells (HUVEC) in vitro ${ }^{56}$. These authors reported that more endothelial cells and new blood vessels were detected in cell cultures treated with EMD than in control group ${ }^{56)}$. Several authors have indicated that EMD has angiogenic activity at the applied sites ${ }^{57)}$, and it can stimulate periodontal cells to produce VEGF ${ }^{58)}$. However, Darwish et al. suggested that enamel matrix derivative, could be preferable material for periodontium, while it is not suitable for dentin-pulp complex regeneration ${ }^{59)}$. Olsson et al. reported similar results by comparing the effect of calcium hydroxide and Emdogain Gel (Biora AB, Malmö, Sweden), consisting of a enamel matrix derivative (EMD) in a propylene glycol alginate (PGA) vehicle, on the postoperative symptoms of the experimentally exposed human dental pulps ${ }^{60)}$. It was shown that the application of Emdogain Gel to the exposed dental pulp causes more inflammation with no effective formation of hard tissue barrier compared with samples subjected to calcium hydroxide application ${ }^{60)}$.

\section{THE EFFECT OF DENTAL TREATMENTS AND MATERIALS ON ANGIOGENESIS IN DENTAL PULP REGENERATION AND REVASCULARIZATION}

The summit goal of the regenerative endodontic procedures is to provide a suitable environment for the regeneration of healthy tissue to restore the lost biological tissues ${ }^{61)}$. The challenge, however, is to create pulp tissue in a vacant canal, which is exactly identical to the pulpal tissue before necrosis and can function properly ${ }^{8,9)}$. This issue is one of the main differences between regenerative attempts and the conventional treatments including apexification. In conventional modalities, the treatment is ended with obturation of empty canal rather than giving it a chance to be filled with biological tissue. The expected clinical and radiographic outcomes of regenerative procedures are the resolution of apical periodontitis, continuity of root development including the length and thickness, and normal responding of regenerated pulp tissue to different pulp tests ${ }^{62,63)}$ (Fig. 3C).

According to current status, previous authors presented a general protocol for pulp regeneration or root revascularization procedures. However, some

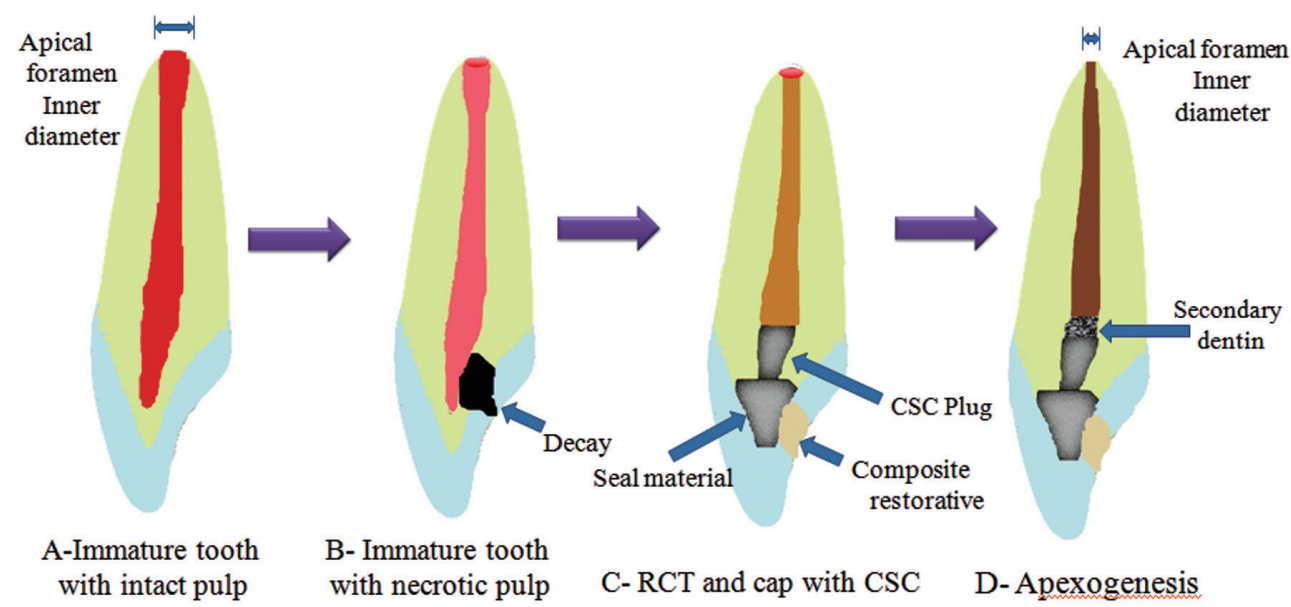

Fig. 3 Schematic presentation of dental pulp regeneration processes in an immature tooth. A: Immature tooth with intact pulp; B: Necrotic dental pulp and accumulation of stem cells of the apical papilla (SCAP) in periapical area; C: Mechanical provocation of bleeding from the periapical site to transport the SCAPs into the empty canal space and establishment of a coronal seal by MTA cement and composite resin materials; D: Formation of pulp-like tissue in apical and mid third of root, which contributes to the maturation of apical third and apical foramen closure by the formation of a cementum-like tissue. 
modifications and improvements have been suggested as well. The overall steps in these procedures included: 1) canal irrigation and disinfection; 2) blood clot formation; and 3) coronal seal to provide appropriate environment for regeneration ${ }^{61,64,65)}$ (Fig. 3). In the following section, the effects of canal irrigating solutions and disinfecting agents on angiogenesis are discussed.

\section{$\mathrm{NaOCl}$}

The first step in dental pulp regeneration is the complete disinfection of root canal system. At first, root canal space should be irrigated with sodium hypochloride $(\mathrm{NaOCl}) . \mathrm{NaOCl}$ has proteolytic and antimicrobial activities which dissolves the organic debris and eliminate microorganisms inside the dental canal ${ }^{66)}$. Bennett et al. evaluated the effect of different antiseptic or antimicrobial agents including 5\% mafenide acetate (Sulfamylon solution), 10\% povidone with 1\% free iodine (Betadine), 0.25\% sodium hypochlorite ("half-strength" Dakin), $3 \%$ hydrogen peroxide, and $0.25 \%$ acetic acid on wound healing. It was indicated that $0.25 \%$ sodium hypochlorite and sulfamylon could significantly increase neodermal thickness and sulfamylon was the most effective agent on promoting angiogenesis ${ }^{67)}$. However, the dilution of sodium hypochlorite can decrease the disinfecting efficiency of this solution. Kozol et al. also suggested that $\mathrm{NaOCl}$ has toxic effects on cells and did not recommend it for use in open wounds ${ }^{68)}$.

Jaimes et al. indicated that $\mathrm{HOCl}$ can inhibit nitric oxide production during inflammation and suggested that this effect might attribute to dysregulation of vascular events and negatively affect the interactions between leukocytes and endothelial cells ${ }^{69)}$. Alkahtani et al. reported that $\mathrm{NaOCl}$ solution has toxic effects on human bone marrow mesenchymal stem cells (MSCs) ${ }^{70}$. Martin et al. also reported that high concentrations of $\mathrm{NaOCl}$ can drastically effect the survival and differentiation of stem cells of the apical papilla (SCAPs) and significantly reduce the expression of dentin sialophosphorprotein (DSPP $)^{71}$. These authors suggested using lower concentrations like 1.5\% and using $17 \%$ EDTA after $\mathrm{NaOCl}$ irrigation reduced the $\mathrm{NaOCl}$ negative effects, and increased the survival rate of SCAPs and expression of DSPP ${ }^{71}$. Trevino et al. also acclaimed that irrigation with $\mathrm{NaOCl}$ can lower the survival rate of SCAPs, while inclusion of EDTA to the irrigation protocol was beneficial and increased the number of viable cells ${ }^{72)}$.

\section{Chlorhexidine gluconate}

The other disinfecting endodontic solution used in regenerative procedures is $2 \%$ chlorhexidine gluconate $(\mathrm{CHX})^{73)}$. The effect of CHX on DPSCs was measured and no viable cell was detected in samples irrigated with $2 \% \mathrm{CHX}^{72)}$. Ring et al. reported that $2 \% \mathrm{CHX}$, as well as $6 \% \mathrm{NaOCl}$, showed cytotoxic effects on DPSCs due to negative influence on their attachment to root canal wall surface ${ }^{74)}$.

\section{EDTA}

EDTA is an endodontic irrigating solution with chelating activity, which is suggested to be added to canal irrigation protocol as a final rinse for smear layer removal or in combination with $\mathrm{NaOCl}$ and $\mathrm{CHX}$ solutions ${ }^{72}$. Ring et al. demonstrated that the absence or presence of smear layer is not as effective on activity of DPSCs ${ }^{74)}$. However, the addition of EDTA to other rinsing solutions can increase the viability of $\mathrm{DPSCs}^{72}$, and positively affect stem cell's attachment to root canal wall ${ }^{74}$. Authors showed that the time of irrigation with EDTA should be $1 \mathrm{~min}$, while after $3 \mathrm{~min}$ the microhardness of dentin can significantly reduce ${ }^{75)}$.

Pang et al. also noted that EDTA can induce DPSCs cell attachment and odontoblastic/osteoblastic differentiation ${ }^{76)}$. Similar to other investigators Galler et $a l$. recommend the usage of EDTA for canal irrigation ${ }^{77)}$. In addition to favorable effect of EDTA on other solutions, it was indicated that EDTA can stimulate the release of pro-angiogenic growth factors in dentin matrix including TGF- $\beta$, VEGF, FGF-2, PDGF, and BMP-2 $2^{33,78,79)}$.

\section{Triple antibiotic paste (TAP)}

TAP is a disinfecting regimen containing three antibiotic pastes including: ciprofloxacin, metronidazole, and minocycline used for complete elimination of microorganisms inside necrotic root canal in regenerative procedures ${ }^{80)}$. Bottino et al. indicated that the scaffolds containing $5 \% \mathrm{wt}$ ciprofloxacin or 5 and $25 \% \mathrm{wt}$ metronidazole were safe for hDPSCs, and only $25 \% \mathrm{wt}$ ciprofloxacin had cytotoxic effects on pulp stem cells ${ }^{81)}$. Bezwada et al. evaluated the intrinsic cytotoxicity of five fluoroquinolone antibiotics including: ciprofloxacin, levofloxacin, ofloxacin, moxifloxacin, and gatifloxacin on human corneal endothelial cells. These authors reported that among these antibiotics, ciprofloxacin showed the highest concentration- and time-dependent cytotoxicity, while levofloxacin had the lowest value ${ }^{82}$. Galley et al. indicated that ciprofloxacin can alter the inflammatory responses in endothelial cells. It was suggested that ciprofloxacin could decrease the expression of inflammatory cytokine IL-6, and increase the expression of the IL-8, a pro-angiogenic cytokine ${ }^{83)}$. Michalska et al. indicated that metronidazole plus clindamycin had anti-agiogenic activity and could strongly interact with pro-angiogenic factors like FGF-2 and fibirin concentration and viscosity ${ }^{84)}$.

Jung et al. demonstrated that minocycline has anti-angiogenic activity due to suppression of the hypoxia-induced vascular endothelial growth factor (VEGF) expression ${ }^{85)}$. These authors also reported that minocycline can inhibit the activity of matrix metalloproteinase $(\mathrm{MMPs})^{85)}$. Li et al. showed that minocycline can accelerate breakdown of hypoxiainducible factor-1 (HIF-1) and inhibit hypoxiainduced neovasculogenesis ${ }^{86}$. Yao et al. reported that minocycline inhibits the migration of human aortic smooth muscle cell (HASMCs) by down-regulating PI3K/ Akt pathway ${ }^{87)}$. Although Arslan et al. recommended the passive ultrasonic irrigation (PUI) with $1 \% \mathrm{NaOCl}$ 
to be useful for removal of the triple antibiotic paste ${ }^{88}$, but the complete removal may not be achieved.

\section{CONCLUSIONS}

The evaluation of angiogenesis events in regenerative endodontic field is quite a new approach in this era. The present review focused on possible influences of dental treatments and materials on angiogenesis during regenerative endodontic procedures, and the following outcomes can be drawn.

- In dentin-pulp complex regeneration, the local angiogenesis events occur at the site of necrotic or injured tissues. Two distinct roles can be considered for pulpal local angiogenesis: 1) the blood supplying the inflammatory phase which should bring the immune cells and components, and the nutrition required for both inflammatory and regeneration phases; 2) the recruitment of perivascular stem cells which in addition to local stem cells can be differentiated into odontoblastlike cells for the production of reparative dentin.

- The dentin matrix might play an important role as a reservoir of intrinsic growth factors. These factors can be released due to changes imposed on dentin structure and also in response to the treatments and materials used on dentin surfaces. In light of this, the pro- or anti-angiogenic properties of dental materials used for dentinpulp complex regeneration should be considered as one of the important characteristics for selecting an ideal dental pulp capping material. This issue was also raised by Tziafas et al. ${ }^{27)}$ besides the traditional criteria such as easy handling, infection control, good sealing ability, and exploiting endogenous signaling for dentinal bridge formation. These authors also mentioned the use of exogenous signaling molecules in new pulp capping strategies ${ }^{9}$.

- In dental pulp regeneration procedures, most of the materials including irrigating solutions or antibiotic pastes have anti-angiogenic effects. However, EDTA solution has pro-angiogenic activity among other solutions. The residual antibiotic paste inside the canal can delay or jeopardize the angiogenesis process. It has been suggested that in future studies, other more biocompatible agents such as levofloxacin, instead of ciprofloxacin, to be evaluated for regenerative procedures.

- Future studies regarding the angiogenic properties of dental materials will lead to a better understanding of their mechanism of action in angiogenesis events at applied area. In addition, the enrichment of these materials with pro- or anti-angiogenic factors can be considered as target goal for regulation and establishment of balanced angiogenesis events. This balanced neoangiogenesis can promote the healing process of dentin-pulp complex on one side and prevent pulp tissue necrosis on the other. The additional biomolecules can enhance the biocompatibility of dental materials as well as their treatment outcomes in regeneration procedures.

Concerning the regenerative endodontics, it should be mentioned that the trend of restoring lost tissue with biological tissues, rather than replacing with synthetic materials, is appreciable and promising. However, the similarity of the structure and functions of restored tissues to the primary tissue must be taken into consideration.

\section{ACKNOWLEDGMENTS}

This publication is dedicated to the memory of Dr. Hajar Afsar Lajevardi, a legendry Iranian pediatrician (19532015) who passed away during the writing of the series of articles regarding the role of angiogenesis in regenerative dentistry. She helped the authors of these article series. We will never forget Dr. H Afsar Lajevardi's kindness and support. She was the only clinician-scientist with a particular focus on infectious diseases of children in Iran. She established Dr. H. A. Lajevardi foundation, with great mission in angiogenesis and regenerative medicine for the next generation of scientists. This work was supported in part by P30 EY016665, and an unrestricted departmental award from Research to Prevent Blindness. Dr. Sheibani is a recipient of a research award from the Retina Research Foundation.

\section{REFERENCES}

1) Saghiri MA, Asatourian A, Sheibani N. Angiogenesis in regenerative dentistry. Oral Surg Oral Med Oral Pathol Oral Radiol 2015; 119: 122.

2) Saghiri MA, Orangi J, Asatourian A, Sheibani N. Functional role of inorganic trace elements in angiogenesis Part II:(Cr, $\mathrm{Si}, \mathrm{Zn}, \mathrm{Cu}$, and S). Crit Rev Oncol Hematol 2015; 96: 143155 .

3) Saghiri MA, Asgar K, Lotfi M, Garcia-Godoy F. Nanomodification of mineral trioxide aggregate for enhanced physiochemical properties. Int Endod J 2012; 45: 979-988.

4) Saghiri MA, Lotfi M, Aghili H. Dental cement composition: US Patent 8, 668, 770, 2014.

5) Saghiri MA, Lotfi M, Saghiri AM, Vosoughhosseini S, Fatemi A, Shiezadeh V, Ranjkesh B. Effect of $\mathrm{pH}$ on sealing ability of white mineral trioxide aggregate as a root-end filling material. J Endod 2008; 34: 1226-1229.

6) Saghiri MA, Asatourian A, Orangi J, Sheibani N. Functional role of inorganic trace elements in angiogenesis Part I:(N, Fe, $\mathrm{Se}, \mathrm{P}, \mathrm{Au}$, and $\mathrm{Ca}$ ). Crit Rev Oncol Hematol 2015; 96: 129142.

7) Saghiri MA, Orangi J, Asatourian A, Sorenson CM, Sheibani N. Functional role of inorganic trace elements in angiogenesis Part III:(Ti, Li, Ce, As, Hg, Va, Nb and Pb). Crit Rev Oncol Hematol 2016; 98: 290-301.

8) Simon S, Goldberg M. Regenerative endodontics: regeneration or repair? The Dent Pulp: Springer; 2014: 267-276.

9) Saghiri MA, Asatourian A, Sorenson CM, Sheibani N. Role of angiogenesis in endodontics: Contributions of stem cells and proangiogenic and antiangiogenic factors to dental pulp regeneration. J Endod 2015; 41: 797-803.

10) Dumsha T, Hovland E. Considerations and treatment of direct and indirect pulp-capping. Dent Clin North Am 1985; 29: 251-259. 
11) Saghiri MA, Asgar K, Daliri M, Lotfi M, Delvarani A, Mehrvarzfar P, Karamifar K. Morphological behavior and attachment of p19 neural cells to root-end filling materials. Scanning 2010; 32: 369-374.

12) Ida-Yonemochi H, Nakatomi M, Ohshima H. Establishment of in vitro culture system for evaluating dentin-pulp complex regeneration with special reference to the differentiation capacity of BrdU label-retaining dental pulp cells. Histochem Cell Biol 2014; 142: 323-333.

13) Mantellini MG, Botero T, Yaman P, Dennison JB, Hanks CT, Nör JE. Adhesive resin and the hydrophilic monomer HEMA induce VEGF expression on dental pulp cells and macrophages. Dent Mater 2006; 22: 434-440.

14) Thibodeau B, Trope M. Pulp revascularization of a necrotic infected immature permanent tooth: case report and review of the literature. Pediatr Dent 2007; 29: 47-50.

15) Lenzi R, Trope M. Revitalization procedures in two traumatized incisors with different biological outcomes. J Endod 2012; 38: 411-414.

16) Keswani D, Pandey R. Revascularization of an immature tooth with a necrotic pulp using platelet-rich fibrin: a case report. Int Endod J 2013; 46: 1096-1104.

17) Nagata JY, Figueiredo de Almeida Gomes BP, Rocha Lima TF, Murakami LS, de Faria DE, Campos GR, de Souza-Filho FJ, Soares Ade J. Traumatized immature teeth treated with 2 protocols of pulp revascularization. J Endod 2014; 40: 606612.

18) Banchs F, Trope M. Revascularization of immature permanent teeth with apical periodontitis: new treatment protocol? J Endod 2004; 30: 196-200.

19) Yamauchi N, Yamauchi S, Nagaoka H, Duggan D, Zhong $\mathrm{S}$, Lee SM, Teixeira FB, Yamauchi M. Tissue engineering strategies for immature teeth with apical periodontitis. J Endod 2011; 37: 390-397.

20) Langer RS, Vacanti JP. Tissue engineering: the challenges ahead. Sci Am 1999; 280: 86-89.

21) Murray PE, Garcia-Godoy F, Hargreaves KM. Regenerative endodontics: a review of current status and a call for action. J Endod 2007; 33: 377-390.

22) Polverini PJ. Angiogenesis in health and disease: insights into basic mechanisms and therapeutic opportunities. J Dent Educ 2002; 66: 962-975.

23) Rafter M. Apexification: a review. Dent Traumatol 2005; 21: 1-8.

24) Garcia-Godoy F, Murray PE. Recommendations for using regenerative endodontic procedures in permanent immature traumatized teeth. Dent Traumatol 2012; 28: 33-41.

25) Nakashima M, Akamine A. The application of tissue engineering to regeneration of pulp and dentin in endodontics. J Endod 2005; 31: 711-718.

26) Zander H. Reaction of the pulp to calcium hydroxide. J Dent Res 1939; 18: 373-379.

27) Tziafas D, Smith A, Lesot H. Designing new treatment strategies in vital pulp therapy. J Dent 2000; 28: 77-92.

28) Schröder U. Effects of calcium hydroxide-containing pulpcapping agents on pulp cell migration, proliferation, and differentiation. J Dent Res 1985; 64: 541-548.

29) Nosrat I, Nosrat C. Reparative hard tissue formation following calcium hydroxide application after partial pulpotomy in cariously exposed pupls of permanent teeth. Int Endod J 1998; 31: 221-226.

30) Ji YM, Jeon SH, Park JY, Chung JH, Choung YH, Choung $\mathrm{PH}$. Dental stem cell therapy with calcium hydroxide in dental pulp capping. Tissue Eng Part A 2010; 16: 1823-1833.

31) Sangwan P, Sangwan A, Duhan J, Rohilla A. Tertiary dentinogenesis with calcium hydroxide: A review of proposed mechanisms. Int Endod J 2013; 46: 3-19.

32) Chun SY, Lee HJ, Choi YA, Kim KM, Baek SH, Park HS, Kim JY, Ahn JM, Cho JY, Cho DW, Shin HI, Park EK. Analysis of the soluble human tooth proteome and its ability to induce dentin/tooth regeneration. Tissue Eng Part A 2010; 17: 181191.

33) Roberts-Clark D, Smith A. Angiogenic growth factors in human dentine matrix. Arch Oral Biol 2000; 45: 1013-1016.

34) Ferrara N, Davis-Smyth T. The biology of vascular endothelial growth factor. Endocr Rev 1997; 18: 4-25.

35) Løvschall H, Tummers M, Thesleff I, Füchtbauer EM, Poulsen K. Activation of the Notch signaling pathway in response to pulp capping of rat molars. Eur J Oral Sci 2005; 113: 312317.

36) Iso T, Hamamori Y, Kedes L. Notch signaling in vascular development. Arterioscler Thromb Vasc Biol 2003; 23: 543553.

37) Al-Hezaimi K, Salameh Z, Al-Fouzan K, Al Rejaie M, Tay FR. Histomorphometric and micro-computed tomography analysis of pulpal response to three different pulp capping materials. J Endod 2011; 37: 507-512.

38) Saghiri MA, Asatourian A, Orangi J, Lotfi M, Soukup JW, Garcia-Godoy F, Sheibani N. Effect of particle size on calcium release and elevation of $\mathrm{pH}$ of endodontic cements. Dent Traumatol 2015; 31: 196-201.

39) Cavalcanti BN, Rode SdM, França CM, Marques MM. Pulp capping materials exert an effect on the secretion of IL- $1 \beta$ and IL-8 by migrating human neutrophils. Braz Oral Res 2011; 25: $13-18$.

40) Norrby K. Mast cells and angiogenesis. APMIS 2002; 110: 355-371.

41) Ferreira DCD, Brito DG, Cavalcanti BN. Cytokine production from human primary teeth pulp fibroblasts stimulated by different pulpotomy agents. J Dent Child 2009; 76: 194-198.

42) Zhang X, Yao Y, Kang H, Dong P. Comparison of expression of transforming growth factor- $\beta 1$ in rat dental pulp during direct pulp capping with 2 capping agents. Shanghai J Stomatol 2014; 23: 154-159.

43) Paranjpe A, Smoot T, Zhang H, Johnson JD. Direct contact with mineral trioxide aggregate activates and differentiates human dental pulp cells. J Endod 2011; 37: 1691-1695.

44) Paranjpe A, Zhang H, Johnson JD. Effects of mineral trioxide aggregate on human dental pulp cells after pulp-capping procedures. J Endod 2010; 36: 1042-1047.

45) Zhang X, Lin Y, Zhao Y. An experimental study of expression changes of inducible nitric oxide synthase in rat dental pulp during direct pulp capping with two capping agents. Hua Xi Kou Qiang Yi Xue Za Zhi 2011; 29: 420-423.

46) Ziche M, Morbidelli L, Masini E, Amerini S, Granger HJ, Maggi CA, Geppetti P, Ledda F. Nitric oxide mediates angiogenesis in vivo and endothelial cell growth and migration in vitro promoted by substance P. J Clin Invest 1994; 94: 2036-2044.

47) Huang SC, Wu BC, Kao CT, Huang TH, Hung CJ, Shie MY. Role of the $\mathrm{p} 38$ pathway in mineral trioxide aggregate-induced cell viability and angiogenesis-related proteins of dental pulp cell in vitro. Int Endod J 2014; 48: 236-245.

48) Asgary S, Nazarian H, Khojasteh A, Shokouhinejad N. Gene expression and cytokine release during odontogenic differentiation of human dental pulp stem cells induced by 2 endodontic biomaterials. J Endod 2014; 40: 387-392.

49) Luo Z, Kohli MR, Yu Q, Kim S, Qu T, He Wx. Biodentine induces human dental pulp stem cell differentiation through mitogen-activated protein kinase and calcium-/calmodulindependent protein kinase II pathways. J Endod 2014; 40: 937-942.

50) Laurent P, Camps J, About I. BiodentineTM induces TGF- $\beta 1$ release from human pulp cells and early dental pulp mineralization. Int Endod J 2012; 45: 439-448.

51) Lutfi A, Kannan T, Fazliah M, Jamaruddin M, Saidi J. Proliferative activity of cells from remaining dental pulp in response to treatment with dental materials. Aust Dent J 2010; 55: 79-85. 
52) Dammaschke T, Stratmann U, Fischer R-J, Sagheri D, Schäfer E. Proliferation of rat molar pulp cells after direct pulp capping with dentine adhesive and calcium hydroxide. Clin Oral Investig 2011; 15: 577-587.

53) Tran-Hung L, Laurent P, Camps J, About I. Quantification of angiogenic growth factors released by human dental cells after injury. Arch Oral Biol 2008; 53: 9-13.

54) Koliniotou-Koumpia E, Tziafas D. Pulpal responses following direct pulp capping of healthy dog teeth with dentine adhesive systems. J Dent 2005; 33: 639-647.

55) Guven EP, Yalvac ME, Sahin F, Yazici MM, Rizvanov AA, Bayirli G. Effect of dental materials calcium hydroxidecontaining cement, mineral trioxide aggregate, and enamel matrix derivative on proliferation and differentiation of human tooth germ stem cells. J Endod 2011; 37: 650-656.

56) Yuan K, Chen CL, Lin MT. Enamel matrix derivative exhibits angiogenic effect in vitro and in a murine model. $\mathrm{J}$ Clin Periodontol 2003; 30: 732-738.

57) Kauvar AS, Thoma DS, Carnes DL, Cochran DL. In vivo angiogenic activity of enamel matrix derivative. J Periodontol 2010; 81: 1196-1201.

58) Schlueter SR, Carnes Jr DL, Cochran DL. In vitro effects of enamel matrix derivative on microvascular cells. J Periodontol 2007; 78: 141-151.

59) Darwish SS, El Meguid SHA, Wahba NA, Mohamed AA, Chrzanowski W, Neel EAA. Root maturation and dentin-pulp response to enamel matrix derivative in pulpotomized permanent teeth. J Tissue Eng 2014; 5: doi: 10.1177/2041731414521707.

60) Olsson H, Davies J, Holst K, Schröder U, Petersson K. Dental pulp capping: effect of Emdogain Gel on experimentally exposed human pulps. Int Endod J 2005; 38: 186-194.

61) Kumar H, Al-Ali M, Parashos P, Manton DJ. Management of 2 teeth diagnosed with dens invaginatus with regenerative endodontics and apexification in the same patient: a case report and review. J Endod 2014; 40: 725-731.

62) Law AS. Considerations for regeneration procedures. J Endod 2013; 39: S44-S56.

63) Geisler TM. Clinical considerations for regenerative endodontic procedures. Dent Clin North Am 2012; 56: 603626.

64) Hargreaves KM, Geisler T, Henry M, Wang Y. Regeneration potential of the young permanent tooth: what does the future hold? J Endod 2008; 34: S51-S56.

65) Hargreaves KM, Diogenes A, Teixeira FB. Treatment options: biological basis of regenerative endodontic procedures. $\mathrm{J}$ Endod 2013; 39: S30-S43.

66) Rutberg M, Spangberg E, Spangberg L. Evaluation of enhanced vascular permeability of vendodontic medicaments in vivo. J Endod 1977; 3: 347-351.

67) Bennett LL, Rosenblum RS, Perlov C, Davidson JM, Barton RM, Nanney LB. An in vivo comparison of topical agents on wound repair. Plast Reconstr Surg 2001; 108: 675-687.

68) Kozol RA, Gillies C, Elgebaly SA. Effects of sodium hypochlorite (Dakin's solution) on cells of the wound module. Arch Surg 1988; 123: 420-423.

69) Jaimes EA, Sweeney C, Raij L. Effects of the reactive oxygen species hydrogen peroxide and hypochlorite on endothelial nitric oxide production. Hypertension 2001; 38: 877-883.

70) AlKahtani A, Alkahtany SM, Mahmood A, Elsafadi MA, Aldahmash AM, Anil S. Cytotoxicity of QMixTM endodontic irrigating solution on human bone marrow mesenchymal stem cells. BMC Oral Health 2014; 14: 27.

71) Martin DE, De Almeida JFA, Henry MA, Khaing ZZ, Schmidt CE, Teixeira FB, Diogenes A. Concentration-dependent effect of sodium hypochlorite on stem cells of apical papilla survival and differentiation. J Endod 2014; 40: 51-55.

72) Trevino EG, Patwardhan AN, Henry MA, Perry G, DybdalHargreaves N, Hargreaves KM, Diogenes A. Effect of irrigants on the survival of human stem cells of the apical papilla in a platelet-rich plasma scaffold in human root tips. J Endod 2011; 37: 1109-1115.

73) Reynolds K, Johnson J, Cohenca N. Pulp revascularization of necrotic bilateral bicuspids using a modified novel technique to eliminate potential coronal discolouration: a case report. Int Endod J 2009; 42: 84-92.

74) Ring KC, Murray PE, Namerow KN, Kuttler S, Garcia-Godoy F. The comparison of the effect of endodontic irrigation on cell adherence to root canal dentin. J Endod 2008; 34: 14741479 .

75) Saghiri MA, Delvarani A, Mehrvarzfar P, Malganji G, Lotfi M, Dadresanfar B, Saghiri AM, Dadvand S. A study of the relation between erosion and microhardness of root canal dentin. Oral Surg Oral Med Oral Pathol Oral Radiol Endod 2009; 108: e29-34.

76) Pang NS, Lee SJ, Kim E, Shin DM, Cho SW, Park W, Zhang X, Jung IY. Effect of EDTA on attachment and differentiation of dental pulp stem cells. J Endod 2014; 40: 811-817.

77) Galler KM, D'Souza RN, Federlin M, Cavender AC, Hartgerink JD, Hecker S, Schmalz G. Dentin conditioning codetermines cell fate in regenerative endodontics. J Endod 2011; 37: 15361541.

78) Zhao S, Sloan A, Murray P, Lumley P, Smith A. Ultrastructural localisation of TGF- $\beta$ exposure in dentine by chemical treatment. Histochem J 2000; 32: 489-494.

79) Begue-Kirn C, Smith AJ, Ruch JV, Wozney JM, Purchio A, Hartmann D, Lesot H. Effects of dentin proteins, transforming growth factor beta 1 (TGF beta 1) and bone morphogenetic protein 2 (BMP2) on the differentiation of odontoblast in vitro. Int J Dev Biol 1992; 36: 491-503.

80) Windley III W, Teixeira F, Levin L, Sigurdsson A, Trope M. Disinfection of immature teeth with a triple antibiotic paste. J Endod 2005; 31: 439-443.

81) Bottino M, Kamocki K, Yassen GH, Platt JA, Vail MM, Ehrlich Y, Spolnik KJ, Gregory RL. Bioactive nanofibrous scaffolds for regenerative endodontics. J Dent Res 2013; 92: 963-969.

82) Bezwada P, Clark LA, Schneider S. Intrinsic cytotoxic effects of fluoroquinolones on human corneal keratocytes and endothelial cells. Curr Med Res Opin 2007; 24: 419-424.

83) Galley HF, Dhillon JK, Paterson RL, Webster NR. Effect of ciprofloxacin on the activation of the transcription factors nuclear factor B, activator protein-1 and nuclear factor interleukin-6, and interleukin-6 and interleukin-8 mRNA expression in a human endothelial cell line. Clin Sci (London) 2000; 99: 405-410.

84) Michalska M, Palatyńska-Ulatowska A, Palatyński A, Mirowski M, Kaplińska K, Nawrot-Modranka J, Lazarenkow A. Influence of antibiotic therapy on the level of selected angiogenic factors in patients with benign gynecologic tumors-preliminary report. Pharmazie 2011; 66: 619-622.

85) Jung HJ, Seo I, Jha BK, Suh SI, Suh MH, Baek WK. Minocycline inhibits angiogenesis in vitro through the translational suppression of HIF-1 $\alpha$. Arch Biochem Biophys 2014; 545: 74-82.

86) Li CH, Liao PL, Yang YT, Huang SH, Lin CH, Cheng YW, Kang JJ. Minocycline accelerates hypoxia-inducible factor-1 alpha degradation and inhibits hypoxia-induced neovasculogenesis through prolyl hydroxylase, von Hippel-Lindau-dependent pathway. Arch Toxicol 2014; 88: 659-671.

87) Yao JS, Shen F, Young WL, Yang GY. Comparison of doxycycline and minocycline in the inhibition of VEGFinduced smooth muscle cell migration. Neurochem Int 2007; 50: 524-530.

88) Arslan H, Capar I, Saygili G, Uysal B, Gok T, Ertas H, Topcuoglu HS. Efficacy of various irrigation protocols on the removal of triple antibiotic paste. Int Endod J 2014; 47: 594599 . 